\title{
Unilateral generalized morphea: a case report and literature review
}

\author{
Urszula Adamska ${ }^{1}$ Anna Slinko ${ }^{1}$, Agnieszka Białecka', Kaja Męcińska-Jundziłł¹, Piotr Adamski², Rafał Czajkowski ${ }^{1}$
}

${ }^{1}$ Chair of Dermatology, Sexually Transmitted Diseases and Immunodermatology, Faculty of Medicine in Bydgoszcz, Nicolaus Copernicus University in Torun, Poland

2Department of Cardiology and Internal Medicine, Collegium Medicum in Bydgoszcz, Nicolaus Copernicus University in Torun, Poland

Adv Dermatol Allergol 2018; XXXV (4): 425-428

DOI: https://doi.org/10.5114/pdia.2017.70258

According to Peterson's classification, linear morphea is one of five subtypes of localized scleroderma (LS) [1]. Unlike systemic sclerosis (SS), linear morphea and other variants of LS are characterized by lack of visceral involvement, Raynaud's phenomenon, sclerodactyly or nailfold capillary changes [2, 3]. Although extracutaneous manifestations can occur in linear morphea, these are different from the visceral involvement seen in SS [4]. The face, scalp and extremities are usually affected in linear morphea, which can be accompanied by bone involvement, growth retardation and flexion contractures $[4,5]$. From single linear indurated plaques and pigmentary changes, through widespread atrophy of skin and muscles, this form may lead to movement abnormalities and poorly healing ulcers. Dermatomal distribution of the mentioned skin lesions has been observed and available data suggest that sclerotic plaques may be localized along the Blaschko lines [6]. Patients may present with elevated titers of one or more autoantibodies, most commonly antinuclear antibodies (ANA). Although no morphea-specific autoantibodies have been reported, anti-single stranded DNA antibodies (anti-ssDNA) and anti-histone antibodies (AHA) are frequently present in linear morphea [7]. Rheumatoid factor (RF) and anti-topoisomerase Il $\alpha$ antibody can be elevated, but it occurs more often in other forms of morphea, e.g. generalized morphea [8]. Several forms of linear morphea are distinguished, including: linear morphea of the extremities, en coup de sabre, progressive facial hemiatrophy [1], and recently described unilateral generalized morphea (UGM).

A 65-year-old male patient with a history of hypertension and type 2 diabetes mellitus presented with extensive plaques of sclerosis, pigmentary lesions, and atrophy of the skin and muscles on the right side of the body. First signs of the disease were observed at the age of 32. There was no known family history of skin disorders and no history of infection, trauma, drug use or toxic exposure. Despite many years of various treatment, skin lesions localized on the right side of the body were progressing continuously.

Physical examination revealed extensive, unilateral, indurated, hypopigmented and hyperpigmented lesions with a loss of adnexal skin structures, resulting in muscle atrophy of the right upper and lower limbs, right half of the face and torso (Figure 1). The circumferences of the right upper and lower limbs compared with the left side were $9 \mathrm{~cm}$ and $15 \mathrm{~cm}$ smaller, respectively. This difference was greater by approximately $1-2 \mathrm{~cm}$ compared with the previous examination 2 years earlier. Small, not healing ulcerations located on abdominal skin were observed and squamous cell carcinoma in the lesions was excluded by histopathological examination. Noteworthy, no cutaneous abnormalities were observed on the left side of the body. Despite widespread skin lesions and muscle atrophy, no significant internal organ involvement was observed. Chest X-ray and computed tomography revealed degenerative changes of the spine and ribs. Barium esophagography excluded esophageal hernia, gastroesophageal reflux disease and impaired lower esophageal sphincter function. Abdominal ultrasound showed an additional spleen and fatty liver. Histopathological examination confirmed the diagnosis of cutaneous scleroderma.

Complete blood count, urinalysis and other routine laboratory tests were normal, except slightly elevated serum transaminases. Autoantibody screening revealed positive ANA with a titer $1: 640$ of the homogenous and cytoplasmic pattern, positive anti-smooth muscle antibodies (ASMA) and liver kidney microsome type 1 antibody (anti-LKM-1). Laboratory tests performed 2 years

Address for correspondence: Urszula Adamska MD, Chair of Dermatology, Sexually Transmitted Diseases and Immunodermatology, Faculty of Medicine, Nicolaus Copernicus University, 9 Sklodowskiej-Curie St, 85-094 Bydgoszcz, Poland, phone: +48 505453743 , e-mail: urszula.randzio@gmail.com Received: 10.08.2017, accepted: 28.08.2017. 

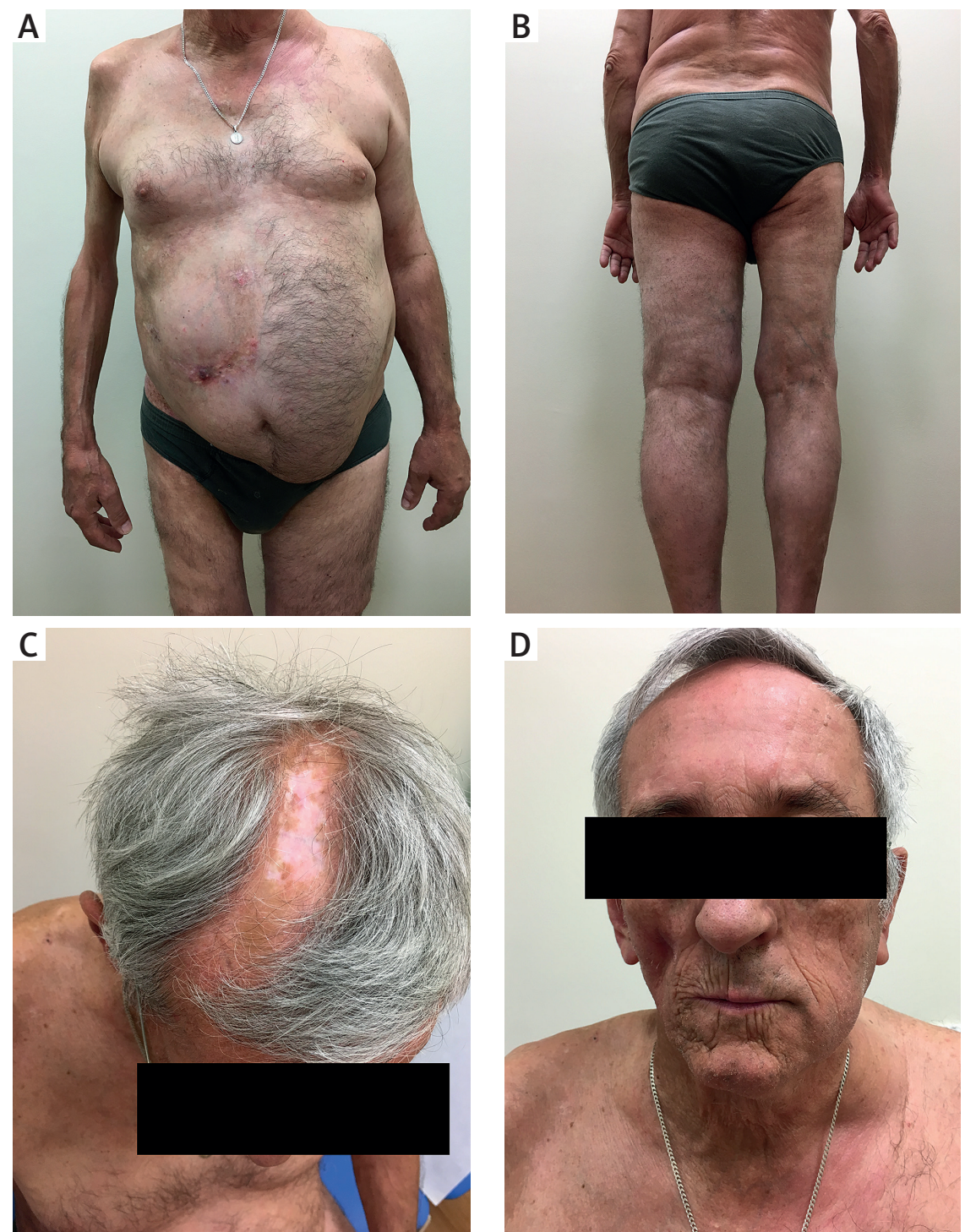

Figure 1. Unilateral, indurated plaques with loss of adnexal skin structures, with muscle atrophy of the chest, abdomen, right upper and lower extremities (A, B), right half of the face and head (C, D)

earlier revealed increased ANA with a titer of $1: 2560$. The diagnostic process for autoimmune liver disease is currently ongoing. RF and Borrelia burgdorferi serology were negative. Genetic testing showed karyotype of $45 \mathrm{XY}, \mathrm{t}(13 ; 14)(\mathrm{q} 10 ; \mathrm{q} 10)$ with Robertsonian translocation between chromosomes 13 and 14, which may explain reproduction failure reported by the patient.

The patient was first diagnosed at the age of 32. According to the clinical and histological features, the diagnosis of Sclerodermia circumscripta generalisata was established. He initially presented only with few plaques, but the condition significantly progressed over time and for this reason the patient was closely followed up. Previous therapy, including vitamin PP and E, procaine penicillin, topical and oral corticosteroids and Bath PUVA, was unsuccessful. During subsequent hospitalization, the diagnosis has been modified, and diagnosis of UGM as a rare variant of the linear form of localized scleroderma was established. The patient received treatment with oral methotrexate (MTX) $12.5 \mathrm{mg}$ per week and prednisone $40 \mathrm{mg}$ daily. Despite the introduced therapy, skin lesions progressed and no improvement was observed, thus the patient was started on cyclosporine $3.45 \mathrm{mg} / \mathrm{kg}$ daily to prevent further progression of the disease.

In 2002, Nagai et al. first reported UGM, an uncommon variant of localized scleroderma. A 6-year-old boy presented with plaques on the right side of the body. Laboratory results revealed ANA with a titer of $1: 320$, elevated concentration of anti-ssDNA and positive RF [9]. Up to date, further six cases of UGM in young adults 
have been described in the literature [10-12]. Moreover, a case of unilateral multisegmental morphea, a subtype of UGM, in an infant was also reported [13]. Similarly to our patient, physical examination of these subjects revealed unilateral hyperpigmentation, indurated plaques, sclerosis or hypopigmentation with skin thickening, and without cutaneous abnormalities on the opposite side. Furthermore, no internal organs were affected nor sclerodactyly or periungular telangiectasia were observed. Only one patient suffered from Raynaud's phenomenon, which was unilateral, too [10]. Laboratory tests revealed positive ANA in all cases, whereas an antibody profile determination was unspecific. Appelhans et al. reported positive ASMA in 2 patients, which were not present in the rest of UGM cases [10]. In addition to ASMA, in our case we observed the presence of LKM-1, which requires further observation for autoimmune liver disease. According to the literature, the rest of chemical and immunological parameters in described UGM patients re- mained within the range. Summary of all reported UGM cases is presented in Table 1.

Unilateral generalized morphea comprises of unilateral skin involvement, early onset of symptoms, positive ANA and negative tests for Borrelia burgdorferi. Besides these common features, no clear diagnostic pattern has been established so far. UGM usually is classified as a very unique variant of linear morphea. Linear morphea accounts for $20 \%$ of LS cases and is the most common form in children and adolescents affecting $64 \%$ of young patients with morphea [4]. However, the onset of UGM may also occur during adulthood, as seen in our patient. The etiology of the disease remains to be delineated. Immunological factors, Borrelia burgdorferi infection and environmental factors, including medications, injections, trauma or radiation therapy have been hypothesized to play a vital role in the pathogenesis of this condition [2-4, 14].

Although no standard therapeutic strategy for UGM exists, different topical and systemic treatment options

Table 1. Summary of all reported unilateral generalized morphea cases

\begin{tabular}{lccccccccc}
\hline Authors [ref.] & $\begin{array}{c}\text { Onset } \\
\text { [age] }\end{array}$ & ANA & $\begin{array}{c}\text { Anti- } \\
\text { dsDNA }\end{array}$ & $\begin{array}{c}\text { Anti- } \\
\text { ssDNA }\end{array}$ & AHA & ASMA & AM A & $\begin{array}{c}\text { Borrelia } \\
\text { RF }\end{array}$ & $\begin{array}{c}\text { Additional } \\
\text { features }\end{array}$ \\
\hline Nagai et al. [9] & 5 & $1: 320$ & Unknown & Positive & Unknown & Unknown & Unknown & Unknown Positive
\end{tabular}

\begin{tabular}{|c|c|c|c|c|c|c|c|c|c|c|}
\hline $\begin{array}{l}\text { Appelhans } \\
\text { et al. [10] }\end{array}$ & 13 & $\begin{array}{c}1: \\
1250\end{array}$ & Negative & Unknown & Positive & Negative & Negative & Negative & Positive & $\begin{array}{l}\mathrm{CIC} \text {, anti- } \\
\text { fibrillarin }\end{array}$ \\
\hline $\begin{array}{l}\text { Appelhans } \\
\text { et al. [10] }\end{array}$ & 17 & $\begin{array}{c}1: \\
2560\end{array}$ & $14 \mathrm{IU} / \mathrm{ml}$ & Unknown & Negative & Positive & Negative & Negative & Negative & $\begin{array}{c}\text { Unilateral } \\
\text { Raynaud's } \\
\text { phenomenon }\end{array}$ \\
\hline $\begin{array}{l}\text { Appelhans } \\
\text { et al. [10] }\end{array}$ & 8 & $\begin{array}{c}1: \\
2560\end{array}$ & $82 \mathrm{IU} / \mathrm{ml}$ & Unknown & Positive & Negative & Positive & Negative & Positive & $\begin{array}{c}\text { Increased level } \\
\text { of PIIIP }\end{array}$ \\
\hline $\begin{array}{l}\text { Appelhans } \\
\text { et al. [10] }\end{array}$ & 4 & $\begin{array}{c}1: \\
1280\end{array}$ & Negative & Unknown & Negative & Positive & Negative & Negative & Negative & \\
\hline $\begin{array}{l}\text { Gerceker Turk } \\
\text { et al. [11] }\end{array}$ & 25 & $1: 320$ & Negative & Negative & Negative & Negative & Negative & Negative & Negative & $\begin{array}{l}\text { Vibration and } \\
\text { silica exposure }\end{array}$ \\
\hline $\begin{array}{l}\text { Rodriguez } \\
\text { et al. [12] }\end{array}$ & 12 & $1: 320$ & Negative & Negative & Positive & Unknown & Unknown & Negative & Negative & $\begin{array}{c}\text { Carpal tunnel } \\
\text { syndrome and } \\
\text { contractures, } \\
\text { mild trauma }\end{array}$ \\
\hline Current case & 32 & $1: 640$ & Negative & Negative & Negative & Positive & Negative & Negative & Negative & $\begin{array}{c}\text { Anti-LKM-1, } \\
\text { karyotype of } \\
45 \mathrm{XY}, \mathrm{t}(13 ; 14) \\
\text { (q10;q10) with } \\
\text { Robertsonian } \\
\text { translocation }\end{array}$ \\
\hline
\end{tabular}

ANA - anti-nuclear antibodies, anti-dsDNA - anti-double-stranded DNA antibodies, anti-sSDNA - anti-single-stranded DNA antibodies, AHA - anti-histone antibodies, ASMA - anti-smooth muscle antibodies, AM A - anti-mitochondrial antibody, RF-rheumatic factor, CIC-circulating immune complexes, PIIIP - human type III procollagen, anti-LKM-1 - liver kidney microsome type 1 antibody. 
used in LS have been proposed to be beneficial in UGM. Topical corticosteroids and calcipotriene therapy should be considered in the active phase of the disease [2]. This therapy was effective in the first described UGM patient [9]. UVA 1 irradiation and PUVA can be used as monotherapy or as a part of combined treatment [10]. Recent studies have shown satisfactory efficacy of systemic corticosteroids and MTX in UGM [10-12]. Cyclosporine A, mycophenolate mofetil, azathioprine, TNF- $\alpha$ inhibitors and other medications used to treat linear morphea seem to be an alternative to the UGM treatment [3]. The existing pharmacological regimens combined with physical and surgical therapy should be an inseparable part of the treatment to avoid development of indivertible damage.

\section{Conflict of interest}

The authors declare no conflict of interest.

\section{References}

1. Peterson LS, Nelson AM, Su WP. Classification of morphea (localized scleroderma). Mayo Clin Proc 1995; 70: 1068-76.

2. Chung L, Lin J, Furst DE, Fiorentino D. Systemic and localized scleroderma. Clin Dermatol 2006; 24: 374-92.

3. Mertens JS, Seyger MMB, Thurlings RM, et al. Morphea and eosinophilic fasciitis: an update. Am J Clin Dermatol 2017; 18: 491-512.

4. Zulian F, Vallongo C, Woo P, et al. Localized scleroderma in childhood is not just a skin disease. Arthritis Rheum 2005; 52: $2873-81$.

5. Tuffanelli DL. Localized scleroderma. Semin Cutan Med Surg 1998; 17: 27-33.

6. Weibel L, Harper JI. Linear morphoea follows Blaschko's lines. Br J Dermatol 2008; 159: 175-81.

7. Dharamsi JW, Victor S, Aguwa N, et al. Morphea in adults and children cohort III: nested case-control study - the clinical significance of autoantibodies inmorphea. JAMA Dermatol 2013; 149: 1159-65.

8. Sato S, Ihn H, Soma Y, et al. Antihistone antibodies in patients with localized scleroderma. Arthritis Rheum 1993; 36: 1137-41.

9. Nagai Y, Hattori T, Ishikawa O. Unilateral generalized morphea in childhood. J Dermatol 2002; 29: 435-8.

10. Appelhans C, Breuckmann F, Gambichler T, et al. Unilateral generalized morphea is a rare variant of localized scleroderma. Eur J Med Res 2006; 28: 152-6.

11. Gerceker Turk B, Urkmez A, Kilinc Karaarslan I, et al. Unilateral generalized morphea: could vibration be a stimulating factor? Clin Exp Dermatol 2010; 35: e165-6.

12. Rodriguez AMF, Martinez MG, Garcia NN. Unilateral generalized morphea: a case and literature review. Reumatol Clin 2011; 7: 404-6.

13. Fleming KF, Wu JJ, Dyson SW, Tsuchiya AM. Unilateral multisegmental morphea. Cutis 2011; 88: 41-2.

14. Budzyńska-Włodarczyk J, Michalska-Jakubus MM, Kowal M, Krasowska D. Evaluation of serum concentrations of the selected cytokines in patients with localized scleroderma. Adv Dermatol Allergol 2016; 33: 47-51. 